\title{
Que horas são? Roberto Schwarz e a crítica do contemporâneo
}

\author{
What time is it? Roberto Schwarz and criticism of contemporary
}

http://dx.doi.org/10.5007/2178-4582.2017v51n2p289

\section{Leonardo Octavio Belinelli de Brito}

Universidade de São Paulo, São Paulo/SP, Brasil

\begin{abstract}
$\mathrm{O}$ artigo analisa as formulações de Roberto Schwarz a respeito da contemporaneidade mundial e brasileira, as quais são inseparáveis. Tomaremos como objetos de análise alguns dos ensaios que o crítico publicou em diversos de seus livros, desde O pai de família e outros estudos, passando por Que horas são?, por Sequências brasileiras e chegando até Martinha versus Lucrécia. A proposta interpretativa do texto é a de que a obra de Schwarz pode ser interpretada como uma reflexão constante - portanto, sempre atualizada - sobre os impasses da modernização brasileira Neste sentido, o trabalho também buscará observar como a dialética materialista, método utilizado por Schwarz, pode indicar as conexões entre os diversos planos que compõem a vida nacional.
\end{abstract}

Palavras-chave: Roberto Schwarz; tradição crítica brasileira; dialética materialista; modernização brasileira.
The article analyzes the formulations of Roberto Schwarz about the world and Brazilian contemporary, which are inseparable. We will take as objects of analysis some of the tests that the critic published in several of his books, from the householder and other studies, passing the time?, by Brazilian sequences and reaching Martinha versus Lucrezia. The interpretation proposed text is that Schwarz's work can be interpreted as a constant reflection - so always up to date - on the impasses of Brazilian modernization In this sense, the work will also seek to observe how the materialist dialectic method used by Schwarz, It may indicate the connections between the various plans that make up the national life.

Keywords: Roberto Schwarz; Brazilian critical tradition; materialist dialectics; Brazilian modernization.

O autor gostaria de agradecer os comentários da professora Maria Elisa Cevasco e do professor Marcos Nobre ao texto. Os equívocos são, no entanto, de sua inteira responsabilidade.

\section{Que horas são? Roberto Schwarz e a crítica do contemporâneo}

Quando se fala em Roberto Schwarz, a reação mais comum é relacionálo aos seus estudos sobre Machado de Assis e ao ensaio, normalmente pouco compreendido, "As ideias fora do lugar" - que consiste, sumariamente, numa tentativa de desvendar as razões pelas quais as ideias e as novas formas, "indispensáveis à modernização do país, causavam não obstante uma irrecusável sensação de estranheza e artificialidade, mesmo entre seus admiradores e adeptos" (SCHWARZ, 2012a, p.167). Naturalmente, a lembrança é justa. Porém, essa ênfase pode ofuscar outras discussões, profundamente ligadas às aludidas, presentes nos ensaios de Schwarz. Isto é: além de um estudioso da aclimatação da forma romance no Brasil - problema luckacsiano (WAIZBORT, 2007, 2009) que só pôde ser adequadamente resolvido por meio do entendimento de planos extra-literários que reverberam 
nas formas dos romances de Machado de Assis "tardio" -, Schwarz é um pensador profundamente ligado aos impasses da sociedade brasileira contemporânea, sempre pensando-a a partir de seus nexos globais. Esse artigo pretende explorar esse ângulo de sua produção intelectual.

Há uma particularidade de se olhar o conjunto de produções de um autor a partir de um momento posterior às suas elaborações: é possível tentar compreender as unidades e rupturas, nem sempre deliberadas, do conjunto. Se os textos acompanharam as realidades dos momentos nos quais foram escritos, como pensamos que é o caso, o conjunto forma um painel cujas linhas evolutivas interessam estudar. É a partir desse "lugar" que procuraremos fazer uma interpretação da obra de Schwarz que buscará destacar os fios de continuidade de suas reflexões. Para realizá-la, partiremos de alguns ensaios recolhidos em O pai de família e outros estudos, passaremos por Que horas são? por Sequências brasileiras e chegaremos ao último livro de Schwarz, Martinha versus Lucrécia. Como se percebe, não abordaremos os livros de Schwarz sobre Machado de Assis - e nem todos os ensaios dos livros analisados, vale deixar claro desde já, em parte porque são estudos mais conhecidos e, principalmente, devido ao espaço curto, que além de dificultar uma abordagem mais abrangente dos ensaios schwarzianos, também impossibilita as construções das mediações exigidas pelos estudos machadianos. Mas deixe-se claro que este caminho é plenamente possível e que nesses estudos há chaves indispensáveis para a compreensão dos sentidos das modernizações brasileiras.

Antes de passar aos ensaios, convém deixar clara qual será a linha que conduzirá a reflexão do texto, qual seja: a modernização brasileira e os vários aspectos que a acompanha, sempre segundo Schwarz. Dito em outras palavras, argumentaremos que o conjunto dos ensaios de Schwarz podem ser lidos como um composto de análises críticas sobre os diversos problemas da modernização do país, sempre percebidos a partir das relações entre questões gerais - como a formação do país e a forma do romance brasileiro - e os impasses conjunturais. Salvo engano, no mesmo sentido vão Anderson Gonçalves, Edu Otsuka e Ivone Rabello quando afirmam que, desde a publicação de "O pai de família (1978), passando por Que horas são? (1987) e Sequências brasileiras (1999), até Martinha versus Lucrécia (2012), cada coletânea, cobrindo mais ou menos uma década, apresenta estudos decisivos para a compreensão de vários momentos da história e da cultura brasileiras" (GONÇALVES, OTSUKA; RABELLO, 2013, p. 328).

\section{As falácias do moderno: a modernização do período 1964-1988}

Os ensaios que compõem Pai de família e outros estudos, cujo texto principal é "Cultura e Política, 1964-1969", tem como eixo ordenador os 
impasses estéticos, políticos e sociais surgidos no contexto do pós-golpe de 1964. Para analisar a forma do livro, é preciso que se tenha em conta uma estratégia recorrente da qual se vale o nosso autor, qual seja: a publicação em separado dos ensaios e seu posterior recolhimento em formato de livro. Assim, quando reunidos em livro, os ensaios costumam ter "sua força potencializada, na medida em que, no conjunto, o debate de ideias, o comentário históricosociológico e a crítica estética, longe de se retraírem em seus nichos, configuram problemas que se cruzam, [...] compondo panoramas complexos dos momentos que acompanharam [...]." (idem, p. 329). Este parece ser o caso do livro em pauta, pois, se observarmos com atenção os ensaios que precedem "Cultura e Política", veremos que eles tocam, em separado, temas que o ensaio principal reunirá: a formação conciliatória das classes urbanas brasileiras, "modernas", em relação às raízes rurais, "atrasadas", em O Amanuense Belmiro, de Cyro dos Anjos; a tensão entre o poder militar supostamente civilizatório e modernizante em relação à sociedade mal-formada do sertão em Os fuzis, a confusão do raciocínio político conservador de Oliveiros Ferreira e a ascensão da indústria cultural em "Nota sobre a vanguarda e conformismo".

Ora, será em “Cultura e Política, 1964-1969" que encontraremos a articulação de várias teses que compõem o seguinte quadro: o golpe de 1964 foi largamente apoiado pelas bases conservadoras do país, que temiam a ascensão popular prenunciada no período anterior; porém, o regime instituído pelos militares não foi "atrasado", ao contrário. Como observou Schwarz, o regime "era pró-americano e antipopular, mas moderno. Levava a cabo a integração econômica e militar com os Estados Unidos, a concentração e a racionalização do capital. Neste sentido o relógio não andara para trás, e os expoentes da propriedade privada rural e suburbana não estavam no poder" (SCHWARZ, 2008a, p. 84).

São vários os tópicos analisados por Schwarz ao longo deste texto: os erros teóricos e estratégicos do Partido Comunista, o caráter histórico do regime militar, as diversas manifestações culturais - ainda dominadas pela esquerda até 1969 , nas quais vibravam fortes energias políticas, por sua vez figuradas em elaborações artísticas de interesse que, apesar de distantes hoje no tempo, ainda nos ajudam a pensar de alguma forma (cf. CEVASCO, 2014, p. 195). Vamos nos deter em um dos casos dessas manifestações, o do Tropicalismo. A escolha do "caso" se dá porque o movimento cultural capitaneado por Caetano Veloso marcará a entrada da indústria cultural no Brasil - constituindo, assim, um episódio chave de nossa modernização cultural.

Caracterizando a experiência social da qual o Tropicalismo tirará suas concepções artísticas, diz o crítico: "a integração imperialista [...], revive e tonifica a parte do arcaísmo ideológico e político de que necessita para a sua estabilidade. De obstáculo e resíduo, o arcaísmo passa a instrumento 
intencional da opressão mais moderna, como aliás a modernização, de libertadora e nacional passa a forma de submissão" (SCHWARZ, 2008a, p. 87). Ora, foi precisamente esse o nexo político e ideológico que tornou o Golpe de 1964 possível: o "atraso" - as classes agrárias alinhadas com o imperialismo norte-americano e com a burguesia nacional - pavimentou um caminho para uma certa realização da modernidade local. É essa combinação, muito frequente na história brasileira, que é em parte trágica, em parte cômica, que aparece em O Amanuense Belmiro e regerá a forma literária em Machado de Assis (SCHWARZ, 2012b).

Segundo Schwarz, o Tropicalismo, no seu próprio procedimento artístico, figura, com novos elementos, essa situação histórica. Como? Ao colocar sob a luz dos meios mais modernos as condições atrasadas do país, agora tidas como insuperáveis. Daí a força dessa construção alegórica, mas nem por isso carente de ambiguidades, que passará a ser a imagem dominante do país até hoje (ALAMBERT, 2012). Nos termos do crítico:

\begin{abstract}
Sistematizando: a crista da onda, que é, quanto à forma, onde os tropicalistas estão, ora alinha pelo esforço crítico, ora pelo sucesso do que seja mais recente nas grandes capitais. Esta indiferença, este valor absoluto do novo, faz que a distância histórica entre técnica e tema, fixada na imagem-tipo do Tropicalismo, possa tanto exprimir ataque à reação quanto o triunfo dos netos citadinos sobre os avós interioranos, o mérito irrefutável de ter nascido depois e ler revistas estrangeiras. Sobre o fundo ambíguo da modernização, é incerta a divisa entre sensibilidade e oportunismo, entre crítica e integração. Uma ambiguidade análoga aparece na conjugação de crítica social violenta e comercialismo atirado [...]. (SCHWARZ, 2008a, p. 88-89). ${ }^{1}$
\end{abstract}

O ensaio de Schwarz deixa claro que o Tropicalismo, no entanto, nasceu no seio da esquerda e representa uma nova sensibilidade diante da vitória do capital. Era uma feição da "nova esquerda" mundial que nascia no terreno ideológico brasileiro. É exatamente por isso que, cerca de quarenta anos depois, Schwarz voltará ao tema para analisar o percurso de Caetano Veloso como percurso típico de nosso tempo (CEVASCO, 2014; SCHWARZ, 2012a). Voltaremos ao tema adiante. De qualquer modo, vale notar a contraposição entre o tropicalismo e a arte nacionalista de esquerda, que se fundamentava numa certa configuração político-estética que perdeu chão histórico com o

\footnotetext{
$1 \quad$ Vale lembrar que em um famoso debate entre os tropicalistas, ocorrido na Faculdade de Arquitetura e Urbanismo da Universidade de São Paulo em 06 de junho de 1968, quando indagado por Chico de Assis sobre as posições tropicalistas, Gilberto Gil foi claro: "E nós estamos aqui para vender. Não fomos nós que fizemos de nossa música mercadoria. Mas ela só penetra quando vendida.”(GIL e VELOSO, 2012, p. 130).
} 
golpe de 1964. Em Verdade Tropical, há a narração do momento no qual Caetano Veloso leu "Cultura e Política 1964-1969" e é a equidistância que o crítico literário estabelece entre as duas posições que chamou a atenção de Veloso no ensaio de Schwarz, embora o músico busque imputar ao crítico literário exatamente o estereótipo da esquerda. Além de um bom exemplo da prosa do músico, o trecho revela o seu típico posicionamento sobre a esquerda, sempre vista de um ponto de vista essencializado. Vale a citação:

Na minha primeira ida de Londres à Paris, ele tinha em mãos
um artigo de Roberto Schwarz sobre o tropicalismo. Era uma
cópia datilografada que o autor - seu amigo - tinha dado a ele.
O artigo era interessante e estimulante. Mas desde já sabia-
se que seria uma versão complexa e aprofundada da reação
desconfiada que a esquerda exibia contra nós. Schwarz não
demonstrava, no entanto, nem hostilidade nem desprezo pelo
nosso movimento. Ao contrário: dava-lhe grande destaque
dentro do esquema que apresentava das relações entre a cultura
e a política do Brasil pós-64. Estávamos longe da rejeição total
que tivemos de um Boal, por exemplo. De todo modo seria uma
honra para mim que o tropicalismo recebesse tanta e tão terna
atenção de um pensador naturalmente tão pouco identificado
com nossa sensibilidade. Era visível, por exemplo, que ele tinha
mais intimidade com o que se fazia em cinema e teatro do que
com o que se passava na música popular. Impressionava-me
que opusesse o método de alfabetização Paulo Freire ao que
os tropicalistas fariam: isso era exatamente uma repetição em
sua teoria do que tinha acontecido em minha vida. Mas sua
redução da "alegoria" tropicalista ao choque entre o arcaico e
o moderno, embora revelasse aspectos até então impensados,
resultava finalmente empobrecedora. (VELOSO, 2008, p. 441 ).

Os anos 80 serão marcados por alguma esperança e muitas batalhas políticas, culturais e econômicas. No campo das expectativas, o surgimento de um partido dos trabalhadores hostil à herança populista e a expectativa do fim do regime militar davam o tom; no campo das dificuldades, além da crise econômica mundial, os impasses culturais locais, integrados ao contexto da produção e circulação capitalista da cultura, na qual tudo se passa como se houvessem "opções" culturais igualmente disponíveis numa espécie de mercado simbólico mundial, também não tornavam as lutas emancipatórias mais fáceis. Ou seja, os traços mercantilizadores da cultura contemporânea que começaram a vigorar no Brasil dos anos 70 se aprofundaram na década seguinte e são tratados por Schwarz em Que horas são?

De saída, note-se a relação estreita entre a discussão sobre o papel das vanguardas nos anos 70 - vanguardas que mudaram de papéis históricos quando passaram a tematizar aperfeiçoamentos técnicos sem horizonte de 
superação, funcionando sob o império da lógica mercantil - e a discussão com o concretismo nos anos 1980. Ao analisar o poema "Póstudo" de Haroldo de Campos, Schwarz observa não só a generalidade da ambição, que anda junto com uma espécie de devaneio de grandiosidade, de mudar "tudo". Afinal de contas, o que significa "tudo"? Não é o caso de entrar nos detalhes da leitura cerrada que Schwarz faz do poema de Campos. Para os nossos propósitos, o que interessa destacar é como Schwarz interpreta o papel da técnica, a vanguarda - a modernização, enfim - nesse poema:

\begin{abstract}
No desenho das letras, salvo engano, estão citados a pop art e a art decô. Notem-se neste sentido o pisca-pisca, efeito dos círculos concêntricos, e o clima ligeiramente passado, que recobre de distância e nostalgia a disposição modernista de mudar tudo. A era presente define-se no mesmo passo, pelo grafismo-chamariz e pela citação arbitrária de estilos, à falta de racionalidade própria. (SCHWARZ, 2012c, p. 60).
\end{abstract}

Para abordar apenas uma das camadas da crítica de Schwarz ao poema de Campos, note-se a combinação entre generalidades e o imperativo da mudança, ainda que não se saiba bem o motivo ${ }^{2}$, se coaduna admiravelmente bem ao contexto contemporâneo de mundialização do capital - afinal de contas, elemento também moderníssimo. A especificação, esforço materialista por excelência, fica de fora e faz as vezes de elemento ultrapassado. E, neste sentido, há semelhanças entre Tropicalismo e Concretismo ${ }^{3}$. Em outros termos: a ênfase na forma - tomada não na sua fundamentação histórica ${ }^{4}$, mas sim em sua dimensão aplainada, como veículo de transmissão de um certo conteúdo - como motor da modernização coloca ambos os movimentos em sentido similar, o da esterilização das possibilidades da arte crítica, pois o que passa a importar é precisamente o veículo e não a mensagem que é transmitida. Aliás, uma certa auto-obsessão compartilhada pelos dois movimentos pode ser vista como sinal disso. De passagem, observe-se que o tom crítico de Schwarz sobre o poema de Campos foi decisivo para a intensificação de um debate sobre a

2 Como observa Schwarz em "Nacional por subtração" (2012c), isso se dá também na própria esfera da produção do conhecimento, como indicam as constantes submissões de pesquisadores aos modismos acadêmicos.

3 Caetano Veloso (2008, p.231) é explícito ao reconhecer a sua dívida com o Concretismo. E é sintomático que enfatize a força da "visão sincrônica" - ou seja, o apagamento da História, dimensão real por excelência -, que causaria, em sua visão, a "superação da oposição centro/periferia." (idem, p. 231).

4 Sobre a questão da relação entre forma e realismo, diz Schwarz: "O abalo que o dinamismo interno da obra inflige à realidade da percepção empírica, ainda a mais sóbria, constitui a poesia e o ensinamento deste arranjo. A forma, nesta acepção, proporciona a experiência do mundo contemporâneo, e faz as vezes de realidade, cujo processo moderno, aliás, para continuarmos com Marx, também se realiza à revelia e pelas costas de seus sujeitos. A integridade total da composição, sem sacrífico da parte de acaso na matéria cotidiana, passa a ser o penhor do acerto estético e o objeto privilegiado da reflexão crítica." (SCHWARZ, 2008b, p. 182-183). 
relação entre arte e sociedade na crítica literária que durou - dura? - bastante tempo (MOURA, 2011, p. 86).

Por outra parte, Schwarz também identifica os equívocos de outra ordem, como fica claro nas polêmicas que estabelece com o chamado "terceiromundismo", um conjunto de correntes que se queriam emancipatórias, porque vinculadas às lutas pelas libertações nacionais dos anos 60 e 70, e desconfiadas da União Soviética. No período, o terceiro-mundismo parecia propor algo inovador em relação ao capitalismo e ao comunismo e possuía, nos termos do crítico, um "clima de profetismo e vanguarda", bem estimulado por artistas que davam "envergadura e vibração estético-política a seu trabalho. Isso sem prejuízo de sua ingenuidade e demagogia, que ficarão igualmente, mas enquanto documento" (SCHWARZ, 2012c, p. 127). Já com relação ao público local, os artistas terceiro-mundistas davam um espetáculo ao almejarem se posicionar no centro da atualidade contemporânea. Porém, em sua avaliação, Schwarz argumenta que o terceiro-mundismo encobria o conflito de classes em prol de uma visada positiva e ingênua sobre as possibilidades emancipatórias da nação, no que seguia, aliás, o nacionalismo retrógrado.

Explicando a sua visão:

\begin{abstract}
Assim, se mesmo em países cuja realidade é bem mais aceitável, o trabalho artístico deve a sua força à negatividade, não vejo porque logo nós iríamos dar sinal positivo, de identidade nacional, a relações de opressão, exploração e confinamento. Estas são a realidade do terceiro mundo, mas não constituem superioridade. (SCHWARZ, 2012c, p.128).
\end{abstract}

Ora, tanto a perspectiva da apologia da integração pela homogeneização cultural como pela especificidade nacional têm em comum justamente o desejo irrefletido de se integrar. Por outro lado, podem resultar em convergências, pois as diferenças - não tematizadas na chave das desigualdades - podem funcionar como se fossem opções de escolhas num contexto no qual elas não põem em jogo os elementos decisivos, de maneira que são tomadas na sua dimensão mais ingênua.

Em Que horas são? a faceta engajada do crítico fica evidente em "Política e Cultura", originalmente formulado como uma plataforma cultural elaborada para o Partido dos Trabalhadores (PT) em 1982. Posicionando-se contra as teses que afirmam que a cultura é um privilégio da burguesia - e que, portanto, não deve ser almejado pelas classes populares -, ou que a cultura não deve ser objeto prioritário dos anseios populares, ou ainda que a cultura popular é pura e assim deve ser preservada, diz o autor: 
A tese desta página vai em direção contrária: com o surgimento dos meios de comunicação de massa, que transformaram muito o processo da expressão e da comunicação social, a questão cultural tornou-se decisiva justamente para o trabalhador. Como democratizar a TV, o rádio, a imprensa, que são o oxigênio e a fumaça que a nossa imaginação respira? Como seria a TV sem manipulação? São perguntas difíceis, mas a luta social efetiva, e sobretudo um projeto de futuro, são impossíveis sem entrar nesse terreno. (SCHWARZ, 2012c, p. 83-84).

Depois de caracterizar os meios de comunicação de massa no Brasil como concentrados nas mãos da classe dominante, como alienadores e homogeneizadores - praticamente toda a população é incorporada pelos meios de comunicação de massa, pouco importando suas divisões sociais, que nem por isso deixam de existir - o autor argumenta que "trata-se, no plano do espírito, de uma expropriação semelhante à que o capitalismo operou no plano da vida econômica. Entretanto, vale a pena insistir em que tanto no caso da economia como no caso da cultura é inviável a volta atrás [...]" (idem, p. 84). Ou seja: se é verdade que os meios de comunicação atuais são parte do aparato social dominante, não é menos verdade que não é possível pensar a democracia contemporânea sem a sua presença. Eis o problema-chave: a modernização não permite voltar atrás - como, bem ou mal, apostava parte dos adeptos do terceiro-mundismo e do nacionalismo (SCHWARZ, 2012c, p. 34) -, mas fazer a apologia de sua atuação no mundo capitalista também não resolve o problema central, o da sua submissão à lógica da mercantilização da cultura.

\section{Nosso fim de século XX e o início do XXI: a modernização colapsada}

Os anos 1990 são marcados pelo apogeu daquilo que se chamou de "globalização". No caso brasileiro, houve o estabelecimento de políticas econômicas de viés neoliberais que sustentavam que a economia brasileira era demasiadamente "fechada" e que o desenvolvimento econômico viria, justamente, por meio da sua integração ao mercado mundial. Tratou-se, como não é difícil de imaginar, de um novo ciclo de modernização.

Os efeitos sociais da forma local de integração ao capitalismo global não tardaram a aparecer e são analisados em Sequências brasileiras. Talvez por reconhecer que estávamos diante de uma nova etapa modernizante, o ponto de partida histórico e lógico das reflexões de Schwarz em Sequências é reconhecimento de que a modernização brasileira não só não cumpriu o que dela se esperava - a integração nacional - como resultou no seu oposto. Daí o interesse do ensaio "Fim de século", no qual o autor sintetiza elementos básicos 
das linhas de força que regeram a história brasileira contemporânea. Como nos lembra o ensaio, nem as dimensões arcaicas do país desapareceram, nem os elementos novos nos redimiram. "Com a distância no tempo e a ampliação da perspectiva, entretanto, essa mesma mescla sofre mais outra vira-volta: deixa de funcionar como emblema nacional, para indicar um aspecto comum das industrializações retardatárias, passado a representar um traço característico da cena contemporânea em seu conjunto (SCHWARZ, 1999, p. 157).

Remontando ao nacionalismo desenvolvimentista, Schwarz assinala a sua tentativa de articular, pela primeira vez, "um imaginário social novo [...] e que aspira, também pela primeira vez, a certa consistência interna: um imaginário no qual, sem prejuízo das falácias nacionalistas e populistas, parecia razoável testar a cultura pela prática social e pelo destino dos oprimidos e excluídos" (SCHWARZ, 1999, p. 157). E mesmo a sua derrota não invalidou tudo, restando "o sentimento das coisas que se havia formado"s. O nacionaldesenvolvimentismo, nascido do mercado interno e industrialização, teve um quê de "epopéia patriótica a partir da construção de Brasília", que tinha no horizonte uma "sociedade nacional integrada, livre dos estigmas coloniais e equiparada aos países adiantados" (SCHWARZ, 1999, p. 157). Mesmo as elites, naquele momento, assumiriam que, para a realização do intento, seria necessário uma articulação de interesses locais independente daqueles próprios aos norte-americanos. Entretanto, o processo de aprofundamento do nacionaldesenvolvimentismo gerou uma convicção mais profunda: para sua realização de maneira antiimperialista, era necessária a mudança da correlação das forças das classes sociais brasileiras. Daí a necessária radicalização social, cortada pelo golpe de 1964, mas nem por isso completamente eliminada: continuava, por exemplo, a animar o Cinema Novo, o pensamento de Celso Furtado e mesmo a Teoria da Dependência.

Com o golpe de 1964, a democratização foi suspensa e o nacionaldesenvolvimentismo volta à baila, agora com feições conservadoras. Ainda assim, alguns intelectuais, mais antiimperialistas e desenvolvimentistas que democráticos, acompanharam com simpatia o projeto militar. Com o fim do período, dadas as crises do petróleo, da dívida e a globalização da economia, os anos 80 indicaram, segundo Schwarz, que "o nacionalismo desenvolvimentista se havia tornado uma ideia vazia, ou melhor, uma ideia para a qual não havia dinheiro" (SCHWARZ, 1999, p. 158). Eis o início do nosso "fim de século", cuja marca é a evidência de que o desenvolvimento pode não ter sido nem nacional e muito menos uma epopéia. "O motor da

5 Talvez essa seja uma chave da valorização da atuação criadora e formativa de Antonio Candido, tal como aparece em Sequências brasileiras. Além disso, essa é precisamente a posição que Schwarz toma no debate que trava com Otília Arantes sobre o papel contemporâneo da arquitetura moderna. 
industrialização patriótica esteve na Volkswagen e os esforços de integração da sociedade brasileira resultaram num quase-apartheid." (SCHWARZ, 1999, p. 158-159). Como resultado, a industrialização criou o que Schwarz chamará, seguindo o pensador alemão Robert Kurz, de "sujeitos monetários sem dinheiro", fórmula que designa os sujeitos integrados na lógica capitalista da vida contemporânea sem condições efetivas de dela participar.

Essa tragédia social não é particular do Brasil, ainda que conte com feições locais. Para localizar a dimensão mundial do processo, o crítico literário recorre ao diagnóstico contemporâneo feito por Kurz em $O$ colapso da modernização. Segundo o teórico alemão, o capitalismo contemporâneo seria marcado pela falta de necessidade do trabalho humano, o que se deve às evoluções tecnológicas com as quais conta. Assim, massas populacionais ao redor do globo se tornariam sujeitos economicamente supérfluos, porque nem trabalhadores, nem consumidores. No caso da periferia, a situação é ainda pior porque os custos da modernização tornam-se proibitivos, condenando grande parte dos países ao âmbito das modernizações falhadas. De passagem, vale notar que essa parece ser precisamente a tese de Francisco de Oliveira em O ornitorrinco (2003). Como diz Schwarz no prefácio escrito ao ensaio do amigo. "Trata-se de um quadro de "acumulação truncada" [...] em que o país se define pelo que não é; ou seja, pela condição subdesenvolvida, que não já não se aplica, e pelo modelo de acumulação, que não alcança" (SCHWARZ, 2012a, p. 156) ${ }^{6}$.

Ora, são precisamente os sujeitos monetários sem dinheiro e a falência do projeto de integração nacional que dão as tônicas dos romances de Chico Buarque, Estorvo, e Paulo Lins, Cidade de Deus, ambos analisados por Schwarz em Sequências brasileiras. Para os que partilham da posição da crítica dialética, a coincidência não é casual: deve-se à forte ligação entre forma artística e processo social que a arte pode ter nos seus melhores casos.

No caso do romance de Chico Buarque, o que se percebe é a decadência de uma classe média carioca da qual o protagonista é membro-herdeiro. Filho de militar - apoiador do golpe de 1964?- o narrador-protagonista anda à solta pelo Rio de Janeiro, que é marcado pela delinquência generalizada. Depois da crença, própria do populismo do período nacional-desenvolvimentistade que a pureza popular sanaria os mal-feitos da elite, Schwarz constata que "chegamos agora a um atoleiro de que ninguém quer sair e em que todos se dão mal" (SCHWARZ, 1999, p. 179). O vazio deixado pela leitura do livro passa, então, a ser qualidade estética, na medida em que figura um traço da percepção contemporânea sobre os horizontes fechados do futuro. Se lembrarmos que

6 Isso a despeito do próprio Francisco de Oliveira (1993) ter recebido com muitas reticências a tese de Kurz, quando da tradução de $O$ colapso da modernização (1992) para o português. 
1988 foi marcado pela chamada "constituição cidadã", que prometia, apesar do contexto econômico difícil em que foi elaborada, um salto civilizacional para o país, e que o livro referido de Chico Buarque foi publicado em 1991, pode-se perceber a intensidade do processo de desmanche pelo qual o país passou. Como afirma o autor:

\begin{abstract}
Note-se que a tônica do romance não está no antagonismo, mas na fluidez e na dissolução das fronteiras entre as categorias sociais - estaríamos nos tornando uma sociedade sem classes, sob o signo da delinquência? -, o que não deixa de assinalar um momento nacional. Ainda assim, não se entende o nivelamento sem considerar as oposições que ele desmancha. (SCHWARZ, 1999, p. 179).
\end{abstract}

A afirmação de Schwarz ganha concretude ao observamos que o protagonista não tem função social - desocupado? Jovem rico e rebelde? -, bem como ao analisarmos a maneira como a qual os trabalhadores aparecem no livro, sempre ligados a funções ilegais e precarizadas. Se o narrador não é exatamente um "sujeito monetário sem dinheiro" porque possui uma cidadania herdada de sua condição de classe prévia, os trabalhadores mencionados podem ser realisticamente lidos sob a categoria formulada por Kurz.

O mesmo pode ser dito dos protagonistas de Cidade de Deus, romance de estreia de Paulo Lins, que figura o que seu autor chamou de "neofavela", caracterizada pelo predomínio da guerra do tráfico, elemento ausente na versão anterior das comunidades precarizadas. Cidade de Deus é um romance marcado pela indistinção entre o certo e o errado - norma e exceção - e pela sequência agitada, porém monótona, de sucessivos confrontos e tragédias. No romance de Lins, percebemos uma correlação do maior interesse: ao passo que a criminalidade cresce, a idade dos bandidos diminui. A ação do romance se passa, predominantemente, dentro do espaço da Cidade de Deus, com poucas passagens ocorrendo fora. Quando ocorrem, as situações se passam nos presídios. Desse modo, embora apresente a situação em perspectiva ampla, o desenrolar dos eventos acontece em espaço diminuto. Do ponto de vista literário, esse traço forneceu força ao romance, pois, segundo Schwarz, "ela dramatiza a cegueira e a segmentação do processo" (idem, p. 166).

Neste plano local, o crítico literário indica a potência dos traficantes, que "usaram a cabeça e aprenderam lições duríssimas, isso sem falar na incalculável tensão nervosa que suportam a todo momento. Nem por isso deixam de ser pobres-diabos que morrem como moscas, longe da opulência que nalgum lugar o tráfico deve proporcionar" (idem, p. 166-167).

Aí está uma chave do romance: essa oscilação entre personagens de potência e pobres-diabos, nos termos do crítico literário, "formaliza e dá realidade 
literária à fratura social, que se reproduz também na esfera do crime" (idem, p. 167). De outro lado, o livro usa ferramentas literárias clássicas mas em novos sentidos. Exemplo disso é a aproximação que o crítico faz entre Cidade de Deus e o naturalismo, pois tanto o romance como o movimento cultural têm relação direta com a realidade que investigam. Nesse registro, Schwarz lembra que o romance ficcionaliza, a partir do ponto de vista dos jovens, tomados como objetos de estudos, os resultados da pesquisa da antropóloga Alba Zaluar sobre o crime e a criminalidade no Rio de Janeiro. Além da investigação empírica, o romance se aproxima do naturalismo também pela presença do expediente de recapitulação do passado e o explorar o presente (idem, p. 169). Ora, como entender que semelhanças com providências de um movimento literário mal afamado podem ter se tornado pontos fortes do romance de Lins? Salvo engano, Schwarz aponta que o fato se deve à racionalidade própria que presidiu a confecção do romance, que logrou concatenar técnicas expositivas de maneira reveladora. Guardadas as devidas proporções, vale lembrar, para tornar claro o nosso argumento, da advertência de Schwarz sobre Machado de Assis, segundo a qual o autor de Memórias póstumas de Brás Cubas logrou construir um romance realista usando técnicas anti-realistas (cf. SCHWARZ, 2008b, p. 27).

No campo da novidade histórica, a indiferença pelas mortes dos jovens criminosos é o sinal de sua naturalização no contexto das "neofavelas". Para sentirmos a dramaticidade da situação, basta comparar essa situação com as comoções generalizadas causadas quando os antigos malandros da favela morriam. "Digamos que a forma anterior de marginalidade era bem mais simpática, para não dizer menos anti-social” (idem, p.170).

O quadro composto por Lins, no qual o tráfico de drogas ocupa lugar central na dinâmica social retratada, desqualifica uma série de argumentos que viam nas marcas das trajetórias individuais dos neofavelados as razões para seus destinos infelizes. Frise-se: esses jovens são resultado da exclusão e, ao mesmo tempo, "resultado do progresso, o qual naturalmente qualificam" (idem, p. 171).

\section{O que vem pela frente? Ou A viagem redonda da dialética negativa da volubilidade}

Em Martinha versus Lucrécia, o diagnóstico do contemporâneo é feito de maneira diferente daquela utilizada em Sequências brasileiras. Ao invés de aprofundar a discussão dos dias atuais, Schwarz se volta para o passado para compreender o "percurso de nosso tempo". Como observam Gonçalves, Otsuka e Rabello: 
Em vez disso, Martinha versus Lucrécia, à vista desarmada, dá a impressão de apenas retomar problemas já formulados em ensaios anteriores, comentar o percurso do próprio autor (em duas das entrevistas) e compor uma coleção de retratos de intelectuais de que Schwarz esteve próximo nos anos 1960. No entanto, o desconcerto inicial do leitor exige que ele se lance à atividade da compreensão. Embora os ensaios de Martinha versus Lucrécia sugiram afastamento em relação às urgências do presente, o reexame dos anos em torno de 1964, recorrente nos textos do livro, permite pensar a ditadura como o momento em que se iniciou a contemporaneidade. (GONÇALVES, OTSUKA; RABELLO, 2013. p. 331-332).

Ora, o conjunto dos vários retratos sobre intelectuais locais - Gilda de Mello e Souza, Bento Prado, Michael Lowy, Sérgio Ferro, além de Giannotti e de entrevistas nas quais narra sua própria trajetória - forma um panorama analítico da geração de Schwarz. Todos, cada um à sua maneira, fizeram parte do processo de institucionalização das ciências humanas no país como também foram figuras importantes na resistência à ditadura inaugurada em 1964. Nesse sentido, revisitar a trajetória de colegas e a sua própria fornece a Schwarz o álibi para pensar alguns dos principais impasses da inteligência nacional que, aliás, chegou às diversas instâncias governamentais do país. Comentando esse assunto, diz Schwarz:

O fenômeno é notável e não foi suficientemente discutido. Contudo, o grande sucesso social-político da geração da resistência teve seu preço. Conforme esta ocupava as novas posições, deixava cair as convicções intelectuais anteriores por realismo, por considerar que estavam obsoletas, por achar que não se aplicavam no momento, por concluir que sempre estiveram erradas, ou também por oportunismo. De modo que o êxito da esquerda foi pessoal e geracional, mas não de suas ideias, das quais ela foi se separando, configurando algo como um fracasso dentro do triunfo, ou melhor, um triunfo dentro do fracasso. Talvez se pudesse dizer que parte do ideário de esquerda se mostrou surpreendentemente adequada às necessidades do capital. $\mathrm{O}$ respeito marxista pela objetividade das leis econômicas não deixava de ser uma boa escola. Seja como for, a tendência é tão numerosa, e aliás espalhada pelo mundo, que uma crítica de tipo moral não alcança o problema. (SCHWARZ, 2012a, p. 219).

Não é o caso de analisar cada um dos retratos. Destaquemos um: o de Sérgio Ferro, de quem Schwarz se aproximou ao longo dos anos 1970, quando se reuniram para ler $O$ Capital junto a outros colegas (RODRIGUES, 2016). $\mathrm{O}$ caso de Ferro é interessante porque o arquiteto tomou o rumo oposto ao 
do ritmo das coisas, isto é, optou pela a recusa aos aspectos alienadores da modernização local. Ferro, engajado desde jovem, não só descobriu a mudança de sentido da modernização brasileira causada pelo golpe, como foi à luta armada para derrubá-lo; além disso, também percebeu, ao estudar a economia política do canteiro de obras, que o modernismo arquitetônico, matriz do que havia de melhor em se tratando de progressismo à época, tinha aspectos conformistas. As descobertas de Ferro tiveram implicações. "O efeito imediato delas entretanto foi o encerramento da atividade de arquiteto de Sérgio, que ficou sem campo prático de trabalho e se recolheu ao ensino e à pintura. Foi o custo a pagar pela consequência, ou também o prêmio que esta the proporcionou" (idem, p. 221). Nesse sentido, ficam claros os limites da opção de Ferro, sem prejuízo de seus acertos teóricos e da seriedade de sua posição moral - que, se é válida, não deixa de ter limites como posição política. Correndo o risco da repetição: as contradições ensejadas pela modernização não são resolvidas nem pela hostilidade completa com relação a ela, como não são melhoradas pela sua apologia.

Em sentido similar ao dos retratos, Schwarz analisa $O$ ornitorrinco, ensaio de Francisco de Oliveira7. Dizemos "similar" porque, embora o texto de Schwarz seja um prefácio, a publicação em conjunto do novo ensaio de Oliveira, em 2003, com o seu Crítica da razão dualista, de 1972, permitiu ao crítico colocar em questão os nexos sociais - isto é, as permanências e as mudanças e suas (novas) articulações na sociedade brasileira - analisados nos dois ensaios de Oliveira.

Segundo Schwarz, se Crítica da razão dualista buscava apontar maneiras de lidar com os entraves do subdesenvolvimento, $O$ ornitorrinco analisa quais foram os impactos da modernização brasileira, que transformou o país num "monstrengo social". Segundo Oliveira, essa metamorfose monstruosa teria ocorrido no momento em que alguns países deram um salto nas forças produtivas, o que não conseguimos reproduzir. A Terceira Revolução Industrial seria uma mistura de mundialização do capital com a expansão dos conhecimentos técnico-científicos, que não possuímos e estaríamos proibidos de possuir devido às patentes. Ademais, a velocidade de produção tecnológica torna inútil aquisição avulsa dos novos aparatos. Dessas circunstâncias conclui o crítico literário: "Nessas circunstâncias de neoatraso, os traços herdados do subdesenvolvimento passam por uma desqualificação suplementar, que compõe a figura do ornitorrinco" (SCHWARZ, 2012a, p. 153). Sem forçar

$7 \quad$ Francisco de Oliveira (2007) conta que o ensaio "Fim de século", de Schwarz, foi tomado como plataforma inicial para uma pesquisa que o CENEDIC desenvolveu. "Tentamos mapear os "desmanches" da ordem "getulista" como dizem seus adversários pela direita, Fernando Henrique Cardoso e Lula - que a luta social, o conflito de classes, para chamá-lo pelo seu nome clássico, havia transformado em direitos do trabalho, eixo central da modernização da sociedade brasileira e referência principal do cálculo econômico burguês." (Oliveira, 2007, p. 150). 
a mão, não deixa de ser sugestiva, nesse sentido, lembrar da observação de Schwarz segundo a qual "o ensaísmo periférico de qualidade sugere a existência de certa linearidade indevida nas construções dialéticas de Adorno e do próprio Marx - uma homogeneização que faz supor que a periferia vá ou possa repetir os passos do centro"(idem, p.49).

A precarização do trabalho e tudo o que a acompanha - desmanche de direitos, informalização do trabalho, as "ocupações" - indicam que o capitalismo perdeu o seu lado civilizatório. Excluídos da competição internacional por tecnologia e com uma sociedade precarizada, o Brasil-ornitorrinco figura uma "sociedade derrotada". Se é verdade que a burguesia nacional optou pela derrota - como teorizou Fernando Henrique Cardoso quando intelectual de esquerda, a quem Oliveira acompanha -, houve uma porta aberta para o salto do desenvolvimento. "Mesmo não aproveitadas, ou deliberadamente recusadas, as brechas do período circunscrito pela Segunda Revolução Industrial quando ciência e tecnologia ainda não estavam monopolizadas - existiam" (idem, p. 154). Não somos, pois, nem subdesenvolvidos, nem alcançamos um estágio mais elevado. Daí a metáfora com o ornitorrinco, um bicho que não é nem isso, nem aquilo. O prefaciador observa que $O$ ornitorrinco foi escrito "em espírito de revisão conclusiva", mas sem negar a ideias da Crítica da razão dualista. Aponta, contudo, para os motivos das derrotas históricas sofridas pela perspectiva do ensaio anterior. Neste sentido, o novo ensaio tem uma perspectiva de "auto-historicização".

E como fica o campo cultural local diante dessa modernização truncada? Salvo engano, é precisamente isso que Schwarz analisa no seu ensaio sobre Verdade Tropical, autobiografia de Caetano Veloso publicada em 1997, que também é uma história situada do Tropicalismo e da geração que estava ao redor de 1964. Mais: trata-se de um músico popular, de formação de esquerda, que foi perseguido pela ditadura militar. Daí, aliás, que Schwarz interprete Caetano Veloso como uma personagem "típica", na acepção de Lukács, isto é, como um personagem que encarna as contradições e as verdades das linhas históricas tensionadas a partir de uma dada realidade (cf. CEVASCO, 2014, p. 196). Como explica ainda Maria Elisa Cevasco:

Desse ângulo, Caetano personifica e revela por onde passam os caminhos que levam das aspirações e ambições de superação dos entraves do Brasil - o motor das grandes movimentações tanto políticas como culturais dos anos formativos para essa geração que hoje tem mais de 60 anos - às posições de uma "esquerda", com muitas aspas, que diz fazer a única política possível. Pode ser que o tema das gerações seja um dos temas subjacentes ao ensaio, emoldurado por vários pontos de chegada em diferentes projetos [...]. (CEVASCO, 2014, p. 196). 
Vale destacar que Schwarz sublinha a força estética do livro de Veloso e a sua estatura intelectual respeitável. Mas vale notar a peculiaridade de que Verdade Tropical é um livro escrito por um músico popular. Ora, uma das fontes de interesse do livro reside aí, afinal de contas, popular pode significar pouco letrado, marginal, pouco sofisticado, etc. Por outro lado, no sentido moderno, popular significa disseminado, aspecto diretamente ligado à indústria cultural. Se o livro de Veloso representa o que Schwarz chama de "emancipação intelectual da música popular brasileira", cabe observar que como no Brasil o "atraso" e o "moderno" não se chocam, mas se dinamizam, o livro de Caetano Veloso demonstraria que:

Exclusão social - o passado? - e mercantilização geral - o progresso? - não são incompatíveis, como supõem os bempensantes, e sua coexistência estabilizada e inadmissível (embora admitida) é uma característica estrutural do país até segunda ordem. Bem mais do que as outras artes, e a música popular está imersa nesse descompasso, o que a torna nacionalmente representativa, além de estratégica para a reflexão. (SCHWARZ, 2012a, p. 54).

Schwarz acompanha, fazendo leitura cerrada, a narrativa de Veloso, que começa em sua infância. $\mathrm{O}$ jovem Caetano Veloso tinha exata consciência do que se passava nos anos 1960: o programa estético das artes engajadas e da esquerda era mudar a estrutura iníqua do país por meio do reconhecimento do direito à cidadania da enorme parcela da população brasileira situada à margem dos bem situados $\mathrm{O}$ curioso na narrativa de Caetano é a sua mistura de dois tempos distintos, o passado e o presente, o que configura uma certa forma do livro ${ }^{8}$, que busca conciliar, retrospectivamente, aquilo que, quando vivido, era radicalidade.

Dito isso, a altura de visão de Caetano não é estável, sempre ameaçada por descaídas regressivas. Volta e meia a lucidez cede o passo a superstições baratas, à mitificação despropositada do Brasil, à autoindulgência desmedida, ao confusionismo calculado. Em passagens tortuosas e difíceis de tragar, a ditadura que pôs na cadeia o próprio artista, os seus melhores amigos e professores, sem falar no estrago geral causado, é tratada com complacência, por ser ela também parte do Brasil - o que é uma verdade óbvia, mas não uma justificação. O sentimento muito vivo dos conflitos, que confere ao livro a envergadura excepcional, coexiste com o desejo acrítico de conciliação, que empurra para o conformismo e o kitsch. Entretanto, como

8 Destaca-se o sentido adorniano do termo: "Embora se oponha à empiria através do momento da forma - e a mediação da forma e do conteúdo não deve conceber-se sem sua distinção - importa, porém, em certa medida e geralmente, buscar a mediação no facto de a forma estética ser conteúdo sedimentado.” (Adorno, 2015, p. 15). 
num romance realista, o acerto das grandes linhas recupera os maus passos do narrador e os transforma em elementos representativos, aumentando a complexidade da constelação. (idem, p. 57).

Interessa destacar, a posição do jovem Caetano sobre a cultura local. Fugindo ao esquema simplista entre nacionalismo versus imperialismo, o jovem de Santo Amaro da Purificação adotava o rock n'roll como símbolo de inconformismo, o que lhe conferia certa autenticidade diante do atraso com o qual convivia, mas nem por isso deixava de ser uma posição particular e que, por isso mesmo, ia na contramão da recepção passiva do que vem de fora. Pode-se assinalar, com efeito, que mesmo essa posição não deixa de ser marcada pela influência cultural norte-americana, mas convém observar que se tratava do ritmo do mundo àquela altura, ritmo, aliás, marcado pelo fortalecimento do raio de ação da indústria cultural. Em síntese: segundo Schwarz, o jovem Caetano, apesar de crítico do provincianismo de sua cidade natal, não desvalorizava as mediações locais na sua relação com a cultura externa, o que era um achado para alguém de sua idade. Nesse sentido, o crítico literário observa que a oposição formulada por Caetano não era a do local versus o cosmopolita, mas sim entre formas de consumo inconformista versus passiva.

Algo similar continuará a perpassar a trajetória de Caetano depois de sua ida a Salvador. Porém, como traço distintivo, aparece uma dialética entre o anseio pela ruptura radical e o apego às tradições. Aqui aparece, então, um problema já aludido: esta atitude fazia com que Caetano confiasse que todas as tensões terminariam solucionadas, que seria reconhecido pelos adversários e que no final todos sairiam bem. Desse modo, Schwarz sugere que:

Seja como for, o seu traço de personalidade muito à vontade no atrito mas avesso ao antagonismo propriamente dito combinava com o momento brasileiro pré-golpe, quando durante algum tempo pareceu que as contradições do país poderiam avançar até o limite e ainda assim encontrar uma superação harmoniosa, sem trauma, que tiraria o Brasil do atraso e seria a admiração de todos. (idem, p. 65 - grifo nosso)

A ilusão de que as contradições brasileiras seriam superadas harmoniosamente ganham figurações - e, não custa assinalar, registros históricos - na trajetória de Caetano, que tinha um pai simpático à União Soviética e detentor de um quadro de Roosevelt na sala de sua casa. De alguma forma, a filiação de Caetano à bossa-nova ia no mesmo sentido e, segundo Schwarz, a sua exposição acerca do tema é um dos pontos altos do 
livro, com destaque para uma sentença de 32 linhas que é caracterizada pelo crítico como um "olé dialético" (idem, p. 70). Essa filiação de Veloso é um acerto estético, a despeito das eventuais ilusões contidas no programa bossanovista. Trata-se de um acerto porque a bossa-nova reelaborou a influência norte-americana de maneira que esta não interrompesse as linhas de força da arte musical nacional, que foram, ao contrário, reforçadas pelas criações de Tom Jobim, João Gilberto, e outros. Tudo somado, as relações entre Salvador, Santo Amaro, cultura internacional e bossa nova sugeria um movimento (inverossímil) de modernização do país feito de modo harmonioso e sem prejuízo de ninguém, como se ele não contivesse graves contradições.

É o golpe de 1964 que porá tudo isso abaixo e causará repulsa ao Caetano dos anos 60, que se alinhava, apesar das tensões, com a esquerda local. No entanto, esse posicionamento sofrerá mudança brusca depois de que Caetano Veloso assistiu a Terra em Transe, de Glauber Rocha, filme que trata do papel dos intelectuais no contexto do golpe de 1964. Em especial, Caetano destaca uma cena em que o personagem Paulo Martins grita com um sindicalista e diz para as câmeras: "Estão vendo quem é o povo? Um analfabeto, um imbecil, um despolitizado" (VELOSO, 2008, p. 99-100).

A cena, que figurava o desespero diante do ocorrido, foi interpretada por Caetano como uma libertação da relação entre intelectuais avançados e massas populares - ideia cuja base era a morte do populismo. Assim, ao aceitar as palavras de Martins sem mediações, Caetano pensou, segundo Schwarz, no

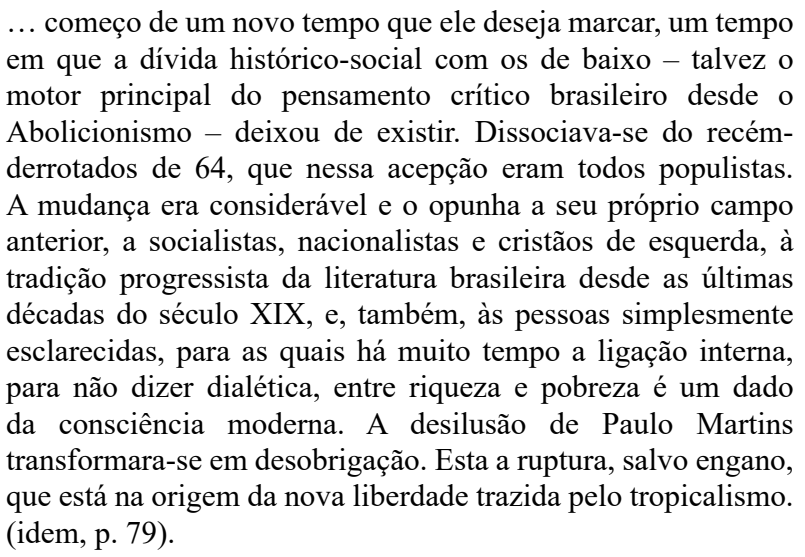

Deste modo, se a esquerda oscilava entre "entregar os pontos" e partir para medidas desesperadas - a luta armada, prefigurada no filme citado -, Caetano via diante de si um futuro repleto de liberdades artísticas a serem exploradas. Saliente-se que o músico adotava posições rebeldes e próximas da contracultura. Mas eis o ponto: ao passo que se opunha à ditadura militar, Caetano passava a se opor, também, à esquerda, vista como defensora de ideologias 
velhas. "Assim, a posição libertária e transgressora postulada por Caetano rechaçava igualmente - ou quase - os establishments da esquerda e da direita, os quais tratava de abalar ao máximo no plano do escândalo cênico, ressalvando, entretanto, o mercado" (idem, p. 81 - grifo nosso).

A ditadura militar é vista, então, por Caetano como: a) reconhecedora do seu potencial subversivo - o que agradava a Caetano, que via nisso um sinal de inteligência superior do regime em relação à esquerda, que o hostilizava; b) aspecto próprio do ser brasileiro contra o qual não haverá rupturas fortes; c) como injusta com ele, que não fazia coisas sérias contra o regime. No mais, assinale-se que Schwarz pontua que quando lemos a sua narração sobre a sua disputa com Geraldo Vandré e sobre sua reação ao incêndio do prédio da União Nacional dos Estudantes (UNE) "assistimos a uma conversão histórica, ou, melhor dizendo, à revelação de que a esquerda, até então estimada, é opressiva e não vale mais que a direita" (idem, p. 87 - grifo do autor $)^{9}$.

Como dito, para Caetano, a esquerda passava a obstruir a inteligência. Em resposta ao diagnóstico, houve a formalização da estratégia estética tropicalista, cujos elementos básicos já mencionamos acima. A disparidade dos elementos conjugados - bossa-nova, João Cabral de Melo Neto, a cultura pop, Chacrinha, o desejo de intervenção e a consequente ambição vanguardista - figura e reafirma os contrastes da realidade. A dimensão propositalmente cínica da arte tropicalista ganha a (des)forma adequada com a ideia de sincretismo, lógica que, segundo Caetano, rege as composições dos alinhados com sua posição. Se era uma posição de força - afinal, fundamentada na realidade -, vale notar o sentido do Tropicalismo para Schwarz:

Acentuando o paradoxo, digamos então que as oposições que o tropicalismo projetava superar eram elas mesmas portadoras de ambição superadora, e que nesse sentido era a própria superação que estava sendo superada, ou, ainda, a própria noção de progresso que estava sendo desativada por uma modalidade diferente de modernização. (idem, p. 97).

\section{Ora, como observa o crítico:}

Por um lado, o artista deixa claro que a imaginação tropicalista é libérrima e se alimenta onde bem entende, sem respeito à hierarquia (elitista? preconceituosa?) que coloca o grande escritor acima da popularidade televisiva. Por outro, a inspiração igualitária não convence, pois na associação de Chacrinha e Sartre há também a alegria debochada de nivelar por baixo, sob o signo emergente da indústria cultural, que rebaixa tanto a gente pobre quanto a filosofia, substituindo por outra, não menos opressiva, a hierarquia da fase anterior. Seria o abismo histórico entre cultura erudita e popular que se estaria tornando coisa do passado? Seria a desqualificação do pensamento crítico pelas novas formas de capitalismo que estaria em andamento? [...]. O gosto duvidoso que a brincadeira deixa na boca é um sabor do nosso tempo. (idem, p. 100).

9 Vale lembrar do discurso de Caetano Veloso no teatro Tuca, em São Paulo, em setembro de 1968, quando criticava a platéia de esquerda que lhe vaiava: "Vocês estão por fora! Vocês não dão para entender. Mas que juventude é essa? Que juventude é essa? Vocês jamais conterão ninguém. Vocês são iguais sabem a quem? São iguais sabem a quem? [...] Àqueles que foram na Roda viva e espancaram os atores! Vocês não diferem em nada deles, vocês não diferem em nada." (Veloso, 2012, p. 169). 
Esse sabor amargo põe em xeque a vigência da crítica dialética. Frisese a potência da questão. Se Schwarz logrou identificar nos seus estudos machadianos os fundamentos históricos do que Paulo Arantes (1992) chamou de "dialética negativa da volubilidade" - subjetividade própria da elite de um país modernamente dualista -, aqui estamos diante desse problema em escala amplificada, pois permeado pela lógica da modernização da indústria cultural, que torna todos os seus elementos equivalentes e regidos sob o mesmo princípio: o do sucesso mercantil. Com a hegemonização desse princípio, os fundamentos de uma arte autônoma - isto é, regida e elaborada segundo outros fundamentos - correm o risco de extinção. É esclarecedora a observação de Schwarz segundo a qual a crítica dialética "supõe obras e sociedades muito estruturadas, com dinamismo próprio" (idem, p. 292). Por outro lado,

\begin{abstract}
Já ninguém pensa que os países de periferia têm uma dialética interna forte - talvez alguns países do centro tenham, talvez nem eles. E no campo das obras, com a entrada maciça do mercado e da mídia na cultura, é voz corrente que a ideia de arte mudou, e é possível que o padrão de exigência do período anterior tenha sido abandonado. Talvez os pressupostos da crítica dialética estejam desaparecendo. (idem, p. 292).
\end{abstract}

Como se viu, esse diagnóstico está calcado nas análises de obras como Estorvo e Cidade de Deus. Por outro lado, a análise schwarziana nos ensina a suspeitar de conceitos e ideias tidos como insuspeitos, como "integração", "modernização", "progresso" e mesmo "democracia". Sem ir pela via de negar os avanços políticos que o país teve após a redemocratização, é decisivo notar que a "integração" dos pobres, almejada pela tradição de autores que tinha como horizonte para o país a "formação" nacional (ARANTES, 1992; ARANTES; ARANTES, 1997), veio, via de regra, pelo sub-emprego e/ou pelo crime e sempre sustentada pela ânsia do consumo mercadológico e não pela vida da cidadania. Naturalmente, esse acontecimento é resultado da "modernização" e do "progresso" da nossa integração ao novo contexto de mundialização do capital. Nesse sentido, até segunda ordem, o potencial cidadão que emergia do conflito entre classes fica suspenso para se dar de outras maneiras, na qual perseveram o ressentimento, a vingança e a predação entre os iguais. (RABELLO, 2015).

No âmbito da cultura, é sintomático que a Tropicália tenha se tornado a visão que exportamos do país e tenha, por isso mesmo, se tornado sucesso de público no exterior (ALAMBERT, 2012). Não menos sintomático é a declaração de Caetano Veloso segundo a qual o sertanejo universitário e o funk carioca "são a Nova Tropicália"10. Vê-se aí que o horizonte entrevisto

$10 \quad$ Fonte: $\underline{\text { http: }} / /$ www.bbc.com/portuguese/noticias/2016/05/160407 caetano mV 
por Schwarz parece correto, afinal de contas, é difícil imaginar que os dois estilos musicais aludidos contenham os elementos necessários de uma obra de arte no sentido adorniano, segundo o qual a grande obra de arte é reveladora. Ao contrário, os dois estilos são marcados pela integração absoluta ao cenário construído pela indústria cultural, no qual contam as evoluções técnicas e o sucesso mercadológico, ambos louvados por Caetano na notícia citada.

No entanto, é verdade que a "contemplação da perda de uma força civilizatória não deixa de ser civilizatória a seu modo" (SCHWARZ, 1999, p. 58). Por outro lado, ao contrário do que dizem alguns, a História não chegou ao fim e o seu relógio continua a andar. Por isso mesmo, apesar das dificuldades que o pensamento crítico contemporâneo enfrenta - algumas delas sumarizadas acima -, é preciso seguir os passos de Schwarz e perguntarse a todo momento: que horas são?

\section{Referências}

ADORNO, T. Teoria Estética. Lisboa: Edições 70, 2015.

ALAMBERT, F. Realidade Tropical. Revista do Instituto de Estudos Brasileiros, São Paulo, n. 54, p.139-150, 2012. Recuperado de http://www.revistas.usp.br/rieb/article/view/49116/53194

ARANTES, P. Sentimento da dialética na experiência intelectual brasileira - dialética e dualidade segundo Antonio Candido e Roberto Schwarz. São Paulo: Paz e Terra. 1992.

ARANTES, O. B. F.; ARANTES, P. E. O sentido da formação hoje. Revista Praga - estudos marxistas, São Paulo, v. 4, p. 95-107, dez./1997.

CEVASCO, M. E. Modernização à brasileira. Revista do Instituto de Estudos Brasileiros. São Paulo, n. 59, p. 191-212, dez./2014.

GIL, Gilberto e VELOSO, Caetano. Debate na FAU. In: COHN, S.; COELHO, F. (Orgs.). Tropicália. Rio de Janeiro: Azougue Editorial. 2012. pp. 126-133.

GONÇALVES, A.; OTSUKA, E. T.; RABELLO, I. D. O retratista e os intelectuais às voltas com 1964. Revista doInstituto de Estudos Brasileiros, São Paulo,n. 57, p. 327-348, 2013. Recuperado de http://www.scielo.br/scielo.php?script=sci arttext\&pid=S0020-38742013000200014

MOURA, F. Um crítico no redemoinho. Tempo Social, São Paulo, vol. 23, n. 2, p. 71-99, 2011. Recuperado de http://www.scielo.br/scielo.php?script=sci arttext\&pid $=$ S0020-38742013000200014

OLIVEIRA, F. De novo, o apocalipse, ou da inutilidade de (o) ser humano. Novos Estudos CEBRAP, n. 46, jul./1993. Recuperado de http://novosestudos.uol.com.br/v1/files/uploads/ contents/70/20080625_o_colapso_da_modernizacao.pdf

OLIVEIRA, F. Crítica à razão dualista/O ornitorrinco. São Paulo: Boitempo Editorial. 2003. 
DE BRITO, L. O. B. Que horas são? Roberto Schwarz e a crítica do contemporâneo.

OLIVEIRA, F. "Um crítico na periferia do capitalismo". In CEVASCO, M. E.; OHATA, M. (Orgs.). Um crítico na periferia do capitalismo: reflexões sobre a obra de Roberto Schwarz. São Paulo: Companhia das Letras. 2007, p. 149-152.

RABELLO, I. O som ao redor: sem futuro, só revanche? Novos Estudos CEBRAP, São Paulo, n. 101, mar./2015. Recuperado de http://novosestudos.uol.com.br/v1/files/uploads/contents/ content_1590/file_1590.pdf

RODRIGUES, L. Leitores e leituras acadêmicas de Karl Marx (São Paulo, 1958-1964). Intelligere, Revista de História Intelectual, São Paulo, v. 2, n. 1[2], p. 1-19, 2016.

SCHWARZ, R. Sequências brasileiras. São Paulo: Companhia das Letras, 1999. . O pai de família e outros estudos. São Paulo: Companhia das Letras, 2008a. . Um mestre na periferia do capitalismo. São Paulo: Editora 34, 2008 b. . Martinha versus Lucrécia. São Paulo: Companhia das Letras, 2012a. Ao vencedor as batatas. São Paulo: Editora 34, 2012 b.

. Que horas são? São Paulo: Companhia das Letras, 2012c.

VELOSO, C. Verdade Tropical. São Paulo: Companhia das Letras, 2008.

Proibido proibir. In COHN, S.; COELHO, F. (Orgs.). Tropicália. Rio de Janeiro: Azougue Editorial, 2012, p. 19-21.

WAIZBORT, L. A passagem do três ao um. São Paulo: Cosac Naify, 2007. Roberto Schwarz: entre forma literária e o processo social. In BOTELHO, A.; SCHWARCZ, L. (Orgs.). Um enigma chamado Brasil - 29 intérpretes e um país. São Paulo: Companhia das Letras, 2009, p. 406-417.

Agência de fomento: CAPES - Cota Institucional (Demanda Social)

Submissão em: 15/09/2016

Aceite em: 25/10/2017

Leonardo Octavio Belinelli de Brito é doutorando em Ciência Política pela Universidade de São Paulo (USP). Mestre em Ciência Política pela mesma instituição. Graduado em Ciências Sociais pela Universidade Federal de São Paulo

(UNIFESP).

E-mail: belinelli.leonardo@gmail.com 